\title{
Morphometrical study of the reproductive tract in Boran (Bos indicus) heifers in Ethiopia
}

\author{
Sayid Ali ${ }^{1 *}$, Tamrat Degefa ${ }^{1,}$ and Alemayehu Lemma ${ }^{2}$ \\ ${ }^{1}$ Ethiopian Institute of Agricultural Research, Debre Zeit Agricultural Research Center, Animal \\ Biotechnology Research Program \\ ${ }^{2}$ Addis Ababa University, College of Veterinary Medicine and Agriculture, Department of Clinical \\ Studies \\ *Corresponding author: -Tel-+251928626835,E-mail: sayid1731@gmail.com
}

\begin{abstract}
Boran breed is the most suitable type of cattle breed for arid and semi-arid regions of Ethiopia due to their adaptive characteristics. Understanding their reproductive anatomy is important for successful reproductive management and has many implications for the application of assisted reproductive technology, and interpretation of physiological changes at different stages of their reproductive cycle. In this study, data of the anatomical structures of the reproductive organs of 20 Boran heifers were measured and characterized at different stages of reproduction. The mean $( \pm \mathrm{SE})$ length $(\mathrm{L})$ of the vagina, cervix, and body of uterus were $13.17 \pm 2.98 \mathrm{~cm}, 7.19 \pm 1.28 \mathrm{~cm}$, and $6.70 \pm 1.08 \mathrm{~cm}$, respectively. The mean $( \pm \mathrm{SE})$ length of the right uterine horn and oviduct was 18.47 \pm 2.54 and $18.17 \pm 1.27 \mathrm{~cm}$, respectively and that of the left were $18.05 \pm 2.73$ and $17.45 \pm 1.80 \mathrm{~cm}$, respectively. The mean $\pm \mathrm{SE}$ weight $(\mathrm{W})$ of right and left ovaries were $2.44 \pm 1.51 \mathrm{gm}$ and $2.44 \pm 1.51 \mathrm{gm}$, respectively. The mean $\pm \mathrm{SE}$ Length $\mathrm{x}$ Width $\mathrm{x}$ Thickness of the right ovary was $2.10 \pm 0.59 \times 1.75 \pm 0.35 \mathrm{x}$ $0.83 \pm 0.36$ and that of the left was $1.97 \pm 0.41 \times 1.58 \pm 0.29 \times 0.67 \pm 0.33 \mathrm{~cm}$. The mean $( \pm \mathrm{SE})$ weight of the whole reproductive organ (without the vulva) was $301.35 \pm 66.34 \mathrm{gm}$. The ovarian size was influenced by the presence of the corpus luteum(CL) usually larger with its presence.
\end{abstract}

Keywords: Boran; Cervix; Fallopian tube; Heifer; Morphometry; Oary; Uterus.

\section{Introduction}

Boran"Indigenous African cattle with potential" are developed in Eastern Africa, more specifically the Borana plateau in Southern Ethiopia. Boran, are the most suitable type of breed for arid and semi-arid regions due to their adaptive 
Ali et al.,

characteristics: tolerance to heat, ticks' infestation, feed, and water shortage (Solomon, 2001). The Boran cow has an excellent mothering ability. As with all zebus, the Boran has good heat tolerance. The sweat glands are more numerous and are larger than those of Bos taurus and the skin surface is increased by the presence of extra folds (Hailemariam et al., 1998).

Animals with Boran genes have a relatively low maintenance requirement. Boran sired steers had a higher level of lipoprotein lipase activity in the subcutaneous fat depot than animals sired by other breeds (Sprinkle et al., 1998). This is an indication that animals with Boran genes have low maintenance requirements, which enables them to survive the periodic feed shortages that frequently occur during drought in their homelands. The most outstanding characteristic of Boran cattle is that, while having low maintenance requirements, they are also able to produce efficiently when feeding conditions improve. Evidence from field data from the Borana Plateau has also demonstrated that young Boran animals can make dramatic recoveries after drought years when pasture conditions improve (Coppock, 1994).

Reproduction is a vital factor in determining the efficiency of animal production. At best, a cow is only likely to produce a single calf per year. The primary reproductive organ in female animals is the ovary, which performs dual roles of oogenesis and steroidogenesis by producing ova and ovarian steroids respectively (Arthur et al., 1989). Other reproductive organs include the oviduct, uterus, and cervix with very important roles in female reproductive capacity and functioning. The semen deposited into the vagina or cervix during ejaculation must navigate the cervical folds and travel upward through the uterine body and the horn to get to the ampulla (Hafeez and Hafeez, 2000). The ovum shed during ovulation is collected by the fimbriae part of the infundibulum and conveyed in opposite directions to meet the spermatozoa usually in the isthmic-ampulla region of the oviduct where fertilization occurs and the formed zygote is transported back to the uterus. The main role of the uterus is to support an embryo during gestation (Ali et al., 2006). The functions of all the aforementioned reproductive parts do overlap and sometimes, require stimulation/inhibition by some products of the other segments. Under normal anatomical and physiological conditions, all these parts work in collaboration and synergistically to achieve maximum reproductive capacity in female animals. Morphometry deals with the shape, weight, and dimension (length, width, and thickness) variation of an organ. The knowledge of reproductive organs' morphometry of female animals (Boran heifers) is crucial and may determine the 
extent to which these organs can perform their physiological roles (Memon, 1996). For instance, the number of cervical rings is related to the length of the cervix and determines the 'hurdles' the sperm has to cross before getting to the uterus. Animals in the luteal phase have slightly or completely curved or C-shaped. From our previous experiment on multiple ovulation and embryo transfer experience, we face difficulty to pass a flushing catheter through the cervix on the day of embryo collection even though the donor has a good response to the technologies. Therefore, for efficient assisted reproductive technology like artificial insemination (AI), embryo flushing, and embryo transfer (ET) information on the morphometry of the reproductive organs is important. The knowledge of such morphometry is also useful for pregnancy diagnosis and investigating cases of infertility in farm animals (Khaton et al., 2015b). There are many reports about the morphometric values of the reproductive tracts of female animals in different countries of the world. However, presently there is a lack of information concerning the morphometry of the female reproductive organs in Boran breeds of cattle in Ethiopia. Therefore, the present study was undertaken to determine the morphometry of the internal reproductive system of Boran heifers in Ethiopia.

\section{Materials and methods}

\section{Sources of the experimental animals}

The study was carried out on 20 Boran heifers de-stocked from the Ethiopian Institute of Agricultural Research (EIAR), in Debre Zeit Agricultural Research Center (DZARC) Bishoftu. Age was estimated based on dentition as described earlier by Lawrence et al. (2001). Accordingly, the study animals were 3 - 4 years of age. The body condition score of the animal ranged from $2.5-3.5$ on a 1-5 scale (1 poor, 5 fat) and was determined as described by Natumyana et al. (2008) Heifers were housed and provided with a feed of different mixes: tef (Eragrostis tef) straw and grass (Andropogon abyssinicus) hay as a basal diet and supplemented with commercially prepared concentrate, mineral salts, and alfalfa green fodder. Water was provided ad-libitum. Animals were regularly dewormed against a common parasitic disease and vaccinated for lumpy skin disease (LSD), foot and mouth disease (FMD), and other common infections. 


\section{Postmortem collection of reproductive organs}

Reproductive organ samples were obtained from heifers de-stocked and slaughtered due to overstocking of the animal resulting in feed and barn shortage at the DZARC farm. Sampled organs were placed in a plastic bag and transported to the laboratory. Then as described by Bhajoni et al. (2018), the ovaries were allocated into two groups: ovary with corpus luteum (CL) and ovary without corpus luteum (CL). All findings were recorded on a predesigned data register.

\section{Measurement of organs}

All measurements length in cm were made using a ruler and Vernier's caliper (Mituoyo Stainless Steel) while weight $[\mathrm{g}]$ was measured using a sensitive electric balance (XY600BJ-1301146 Citizen, Delhi)). The whole reproductive organ was washed with lukewarm water, extra connective tissues were removed, and the weight of the entire tract (Figure 1) was measured and later on made flat on a table before separating individual organs. Each organ was individually measured: Ovaries (length, width, thickness, and weight), oviducts (length), uterine horns (length and diameter) body of the uterus (length and diameter), cervix (length, diameter, and ring), and vagina (length).

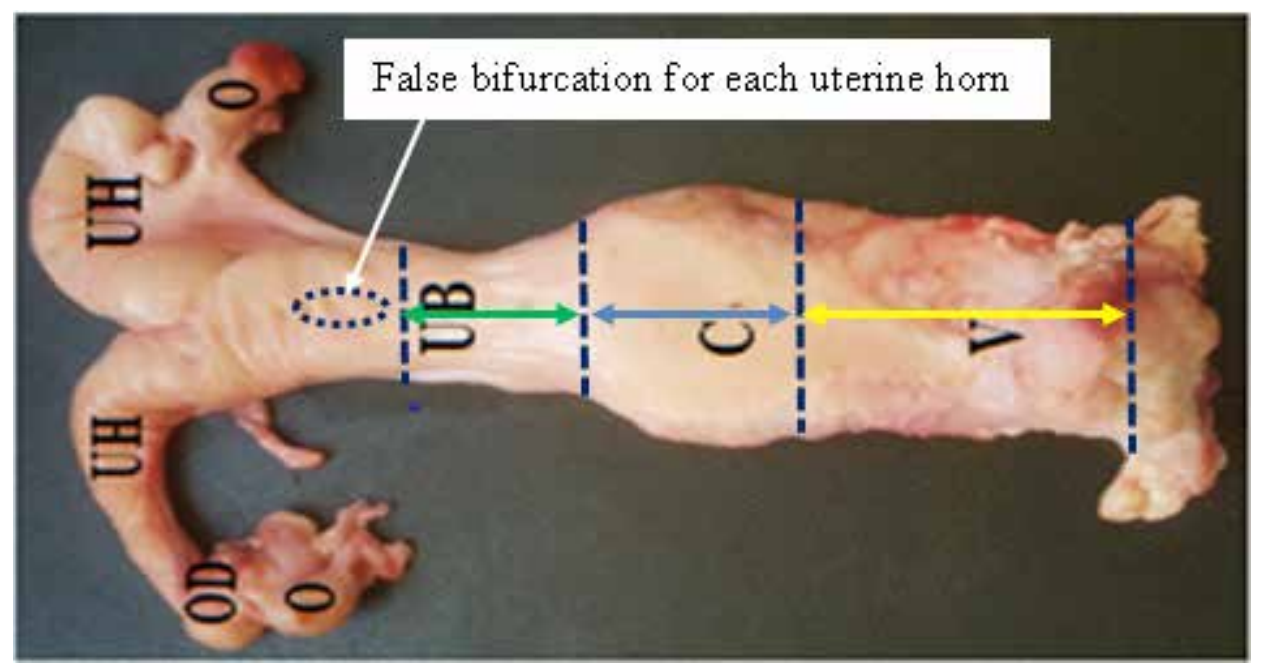

Figure 1. The reproductive system of Boran heifer: $(\mathrm{V})=$ Vagina, $(\mathrm{C})=$ Cervix, (UB) $=$ Uterine body, (UH) = uterine horn, (OD) =Oviduct, $(\mathrm{O})=$ Ovary

The length of the oviduct was taken from the top of the fimbria to the uterotubal junction. The length of the uterine horn was the length from the middle 
of the bifurcation of the uterus to the utero-tubal junction (Figure 2). Diameters of the horn, body, and neck of the uterus were measured across. The length of the uterine body was measured from its bifurcation to the internal os of the cervix. The length of the cervix was the distance from the tip of the internal os to the tip of the external os. The length of the vagina was taken as the length from the external os of the cervix to the vestibule. Cervical rings/folds were considered as the number of rings/folds from os-externum to os-internum (Figure 4).
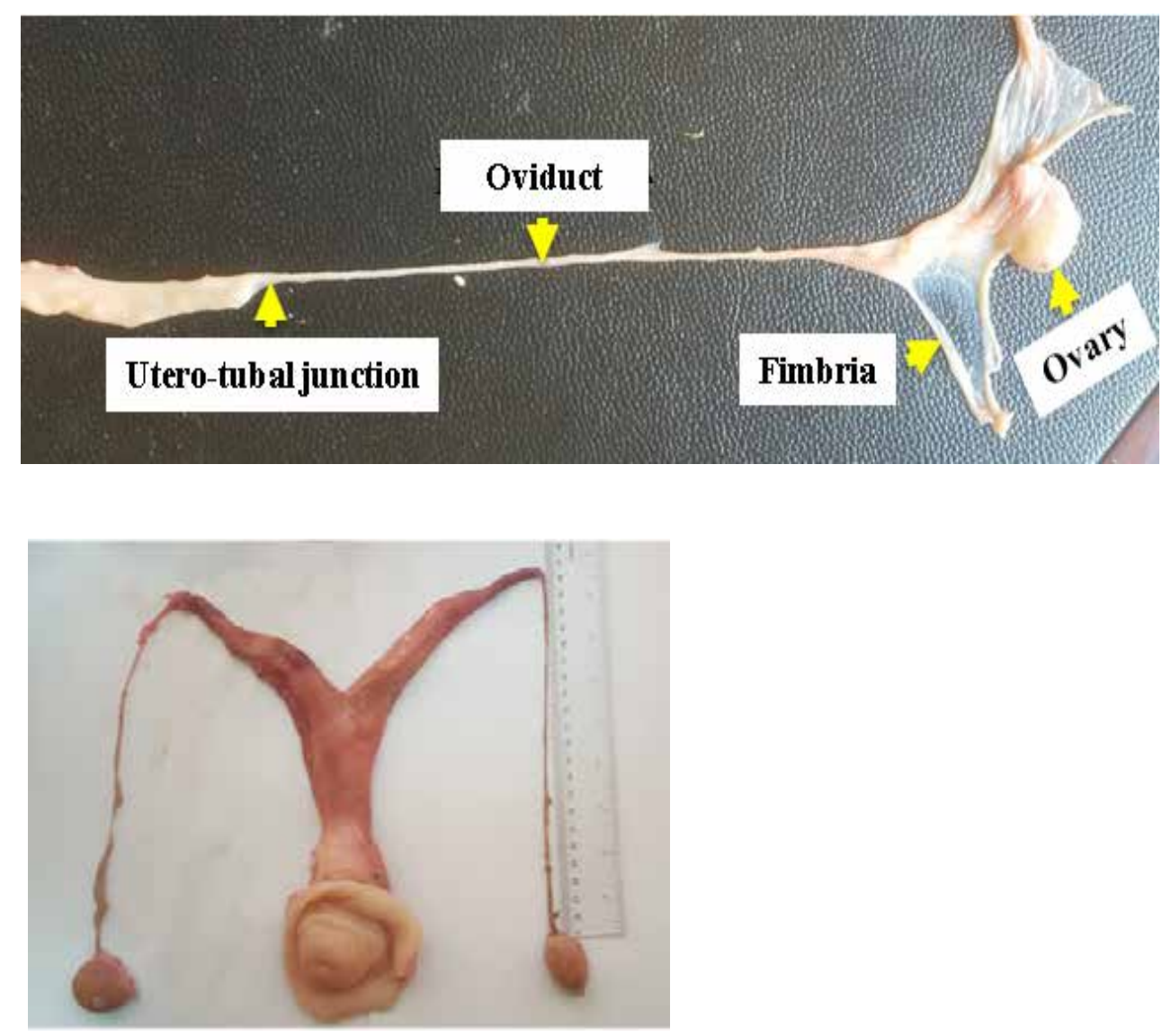

Figure 2. Ovary and oviduct (top), uterine horn and body, and the cervix (bottom) of Boran heifer showing measurement reference points 
The ovaries, right and left were removed at their junction with the ovarian ligament as close to the ovarian tissue as possible after the weight of the whole reproductive organ was taken. Excessive tissues attached to the ovaries were carefully trimmed off and ovaries were weighed separately. The CL was identified when present and its color was classified (reddish=corpus hemorrhagicum $(\mathrm{CH})$, yellowish or orange $=$ mature $(\mathrm{CL})$, and white $=$ corpus albicans $(\mathrm{CA})$; figure 3: The length of the ovary was measured from the anterior pole to the posterior pole along the length. The width of the ovary was measured from the medial to the lateral borders of the ovary. The thickness was measured at the thickest part of the ovary (Kouamo et al.,2017).
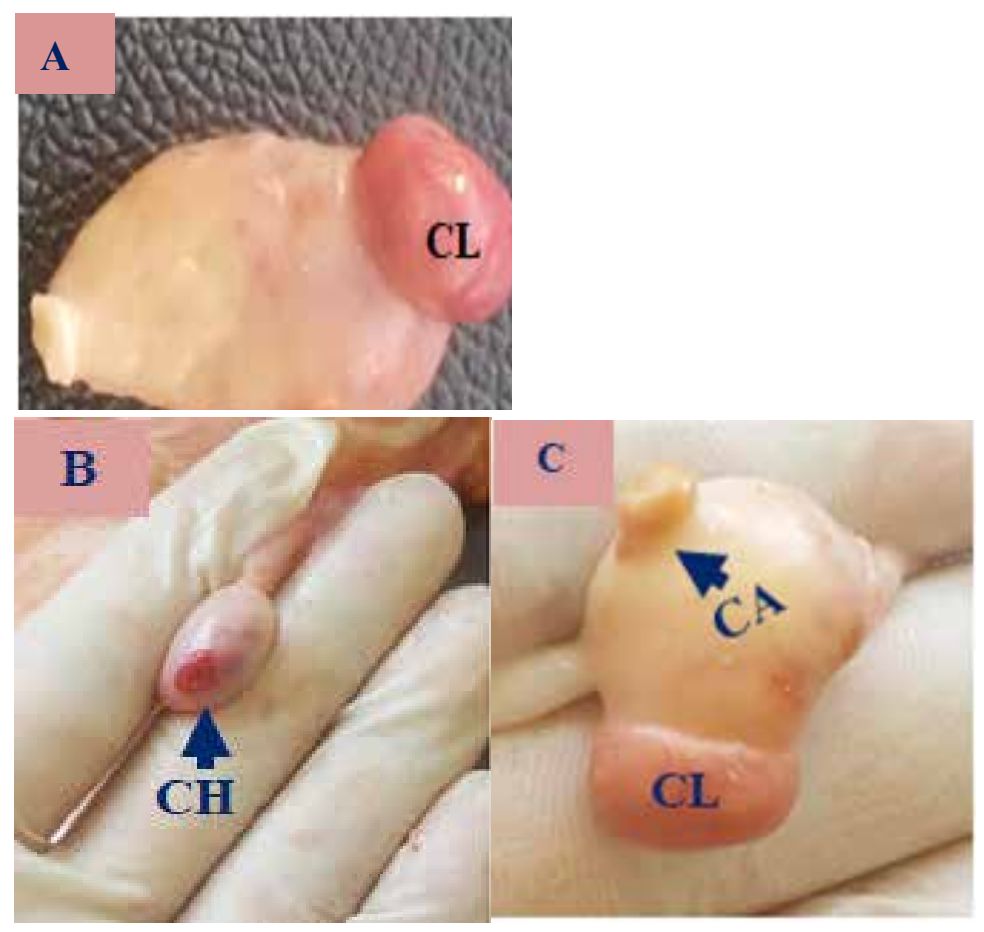

Figure 3. A) Corpus luteum (CL), B) Corpus hemorrhagicum (CH) and C) Corpus albican (CA) and D) Number of cervical rings (CR) 


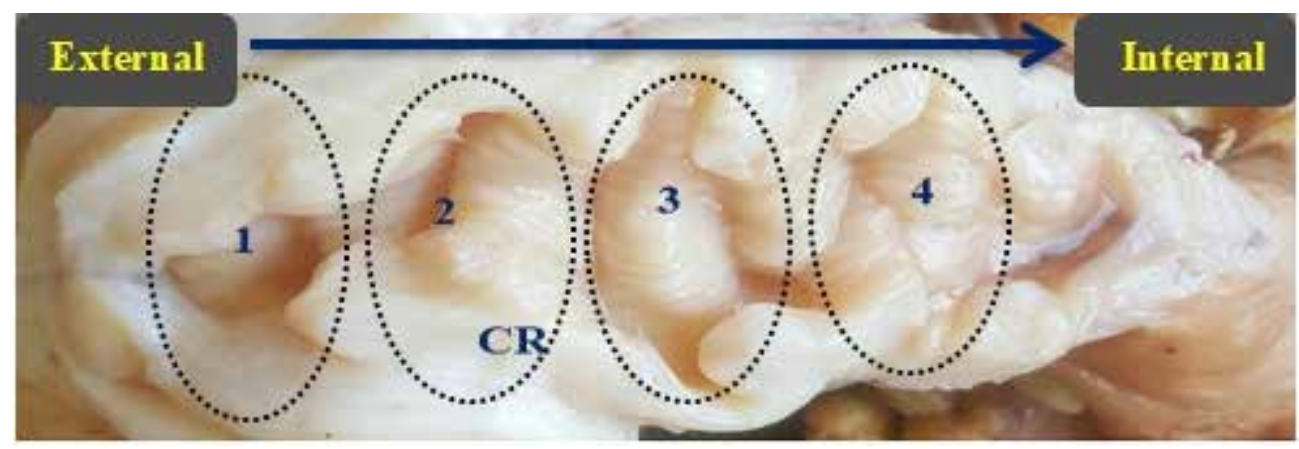

Figure 4. Number of cervical rings (CR), from os-externum (end of vagina) to os-internum (beginning of uterus).

Statistical analysis: In a parametric model, the data were presented as mean \pm standard error. All analyses were performed using SPSS (Statistical Package for Social Sciences) (SPSS 20).

\section{Results}

In this study, ovarian morphometry of Boran heifers was evaluated in terms of length, width, thickness, and weight. Generated data showed that the mean length, width, thickness, and weight right ovaries of $(2.10 \pm 0.59 \mathrm{~cm}, 1.75 \pm 0.35$ $\mathrm{cm}, 0.83 \pm 0.36 \mathrm{~cm}$, and $2.44 \pm 1.51 \mathrm{gm})$ were not significantly $(P<0.05)$ differed compared to that of left ovaries $(1.97 \pm 0.41 \mathrm{~cm}, 1.58 \pm 0.29 \mathrm{~cm}, 0.67 \pm 0.33 \mathrm{~cm}$, and $2.06 \pm 0.93 \mathrm{gm}$, respectively). The mean $( \pm \mathrm{SE})$ weight of the whole reproductive organ (without the vulva) was $301.35 \pm 66.34 \mathrm{gm}$.

On the other hand, findings in ovarian morphometry revealed that the mean weight of ovaries with CL $2.95 \pm 1.60$ was significantly $(P<0.05)$ higher than the mean weight of ovaries without CL 1.67 \pm 0.83 .as shown in Table 2. 
Ali et al.,

Table 1. The mean length, width, thickness, and weight of ovaries in Boran heifers (Mean $\pm \mathrm{SE}$ )

\begin{tabular}{llc}
\hline Organ & Measurements & Mean $( \pm$ SE) \\
\hline Right ovary & Length $(\mathrm{cm})$ & $2.10 \pm 0.59$ \\
& Width $(\mathrm{cm})$ & $1.75 \pm 0.35$ \\
& Thickness (cm) & $0.83 \pm 0.36$ \\
Left ovary & Weight (gm) & $2.44 \pm 1.51$ \\
& Length (cm) & $1.97 \pm 0.41$ \\
& Width (cm) & $1.58 \pm 0.29$ \\
& Thickness (cm) & $0.67 \pm 0.33$ \\
& Weight (gm) & $2.06 \pm 0.93$ \\
\hline
\end{tabular}

Table 2. Comparative dimensions of CL or non-CL bearing ovary (Mean $\pm \mathrm{SEM}$ ).

\begin{tabular}{lcc}
\hline Measurement [cm] & CL bearing ovary (15) & Non CL bearing ovary (25) \\
\hline Width $(\mathrm{cm})$ & $1.87 \pm 0.35$ & $1.52 \pm 0.29$ \\
Length $(\mathrm{cm})$ & $2.25 \pm 0.63$ & $1.86 \pm 0.37$ \\
Thickness (cm) & $0.95 \pm 0.36$ & $0.65 \pm 0.30$ \\
Weight $(\mathrm{gm})$ & $2.95 \pm 1.60$ & $1.67 \pm 0.83$ \\
\hline
\end{tabular}

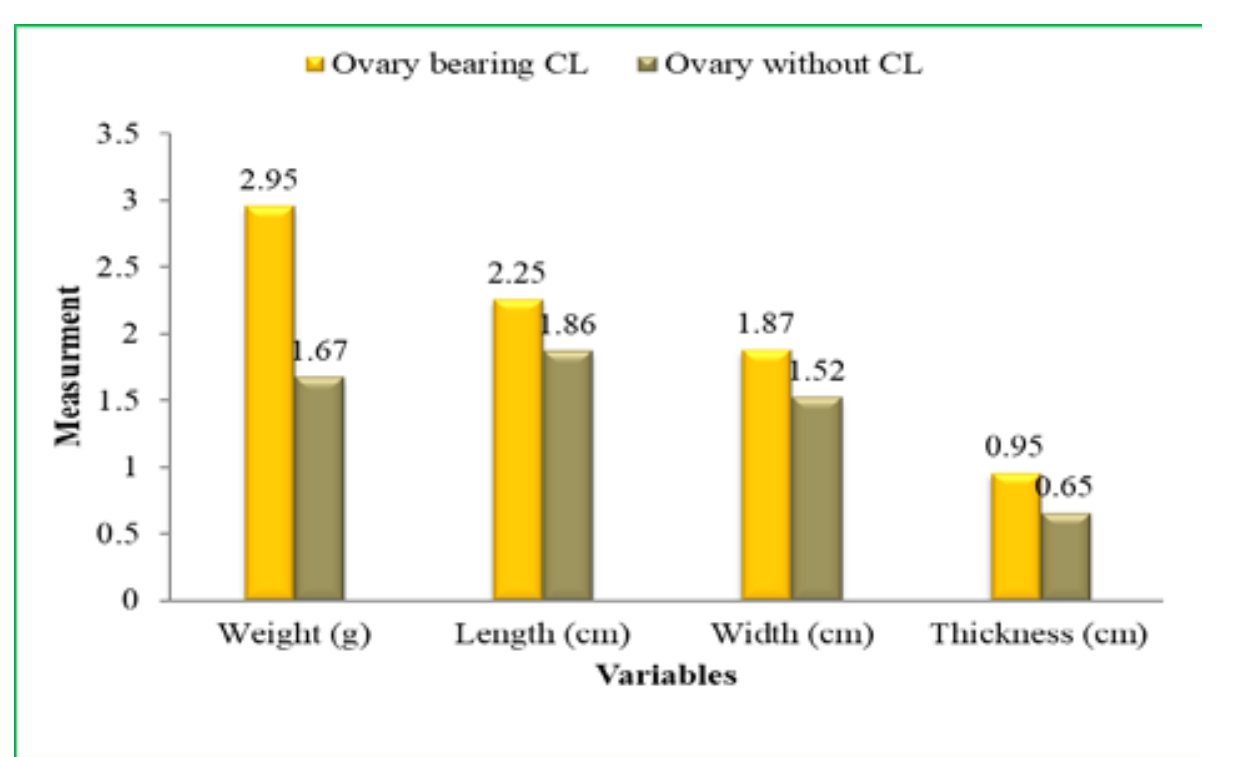

Figure 5. Morphometry of Boran ovary with and without CL 
Table 3. Comparative dimension of uterine morphometry

\begin{tabular}{lcc}
\hline Measurement [cm] & Follicular phase [mean $( \pm$ SE)] & Luteal phase [mean $( \pm$ SE)] \\
\hline Uterine body length & $7.0 \pm 0.72$ & $7.67 \pm 0.91$ \\
Uterine body diameter & $3.56 \pm 0.93$ & $3.7 \pm 0.21$ \\
Uterine horn length & $17.5 \pm 0.57$ & $18.5 \pm 0.44$ \\
\hline
\end{tabular}

Table 4. The mean length and diameter of the tubular part of the reproductive tract of Boran heifers

\begin{tabular}{lc}
\hline Organ measurements [cm] & Mean ( \pm SE) \\
\hline Length of right oviduct [cm] & $18.17 \pm 1.27$ \\
Length of the left oviduct[cm] & $17.45 \pm 1.80$ \\
Length of the right uterine horn [cm] & $18.47 \pm 2.54$ \\
Length of the left uterine horn[cm] & $18.05 \pm 2.73$ \\
Length of the body of uterus [cm] & $7.86 \pm 1.08$ \\
Diameter of the body of uterus [cm] & $3.65 \pm 0.51$ \\
Length of the cervix [cm] & $7.19 \pm 1.28$ \\
Diameter of the cervix [cm] & $3.40 \pm 0.50$ \\
Number of the cervical ring[number] & $3.65 \pm 0.87$ \\
Length of vagina [cm] & $13.17 \pm 2.98$ \\
Weight of whole organ [gm] & $301.35 \pm 66.34$ \\
\hline
\end{tabular}

\section{Discussion}

All reproductive organs, the ovary, oviduct, uterus, and cervix play synergistic functioning in the reproductive system of females (Siddiqui et al., 2005). The knowledge of morphometric parameters of these organs may determine the extent to which they can fulfill and perform their physiological roles towards the attainment of optimal reproductive capacity in female mammals.

Results obtained in the present study indicated that the average length $(\mathrm{cm})$ of oviducts, uterine horns, and cervix commissure of Boran heifers were lower than those reported in another tropical zebu breed however higher in the body of uterus dimension. Accordingly, Moussa Garba et al. (2013) reported an average length $(\mathrm{cm})$ of 19.1, 21.6, 8.2, and 18.9 for oviducts, uterine horns, cervix, and vagina commissure, respectively in Bos indicus breed of cattle. On the other hand, Riasat et al. (2006) reported an average length (cm) for the uterine horns and the cervix of $20.23 \pm 0.23$ and $6.0 \pm 0.22$, respectively in Zebu cow. Further- 
Ali et al.,

more, in dairy cows, Khaton et al. (2015 a) reported an average length $(\mathrm{cm})$ for the oviducts, uterine horns, the body of the uterus, and vagina of 21.03, 25.56, 3.12 , and 22.59, respectively for organs of dairy cows in Bangladesh In other findings reported by Carvalho et al. (2005) in the European breeds; an average length $(\mathrm{cm})$ of 20.5-23.1, 35.3-39, and 4.1 for the oviducts, uterine horns, and uterine body, respectively. However, Kouamo et al. (2017), Khaton et al. (2015 a), and Moussa Garba et al.(2013) reported a lower vagina diameter compared to our finding. This difference could be possibly due to breed (genotype), age, environment, and management factors. Genotype and environmental factors play a crucial role in the productive and reproductive performance of cows/heifers (Kouamo et al., 2017). The adaptation of the reproductive function in the animal's environment may justify the difference between local and European breeds (Kouamo et al., 2017). Indeed, the physical development and maturity of the reproductive tract depend on the age of the animal.

In these findings, the weight and the size (length, width, and thickness) of ovaries obtained were lower than those obtained by Khaton et al. $(2015, \mathrm{~b})$ reported from the local breed of Bangladesh, and their cross with Holstein Friesian, and Jersey breed.

Our findings obtained in the present study indicated that the mean weight of right and left ovaries as well as mean length of right and left ovaries were lower compared to Raheem et al. (2016) report in Red Bororo cow and White Fulani cows. However, Kunbhar et al. (2003) reported mean width $(\mathrm{cm})$ of the right and left ovaries in the Thari cow were $1.33 \pm 0.08 \mathrm{~cm}$ and $1.30 \pm 0.09 \mathrm{~cm}$ receptively which is lower compared to our study. On the other hand, results obtained in the present study indicated that morphometric measurements such as weight, length, width, and thickness were greater in the ovary bearing CL as compared to the non-CL bearing ovary, which is an incomplete argument with Bhajoniet al. (2018) findings.

In this study in most animals' examination of the cervix for an animal in the luteal phase (a functional CL in either ovary), indicate that their cervix is slightly or completely curved (C-shaped) which is difficult to path catheters through the cervix for embryo flushing or embryo transfer. This might implicate due consideration of developing certain procedures and materials that enable to pass through the cervix during the luteal phase or follow alternative techniques for further adoption and implementing the technologies. 


\section{Conclusions}

From this study, it was concluded that the right ovary was wider in diameter, larger in length, and heavier in weight as compared to the left one but not statistically significant. This confirms that the fact of the right ovary being more active than the left one. On the other hand, ovary-bearing CL was significantly wider in diameter, larger in length, and heavier in weight as compared to the non-CL-bearing ovaries.

The difference in the size of the ovaries might be a reason for differences in ovarian activities potentially having implications for conducting other assisted reproductive technologies procedures such as ovum pick up (OPU). To the best of our knowledge, this is the first study to generate and document the morphometric parameters of reproductive organs in the Boran heifer in Ethiopia. These data for this breed may be useful as baseline data in further study related to the physiological function of individual structures measured in this study. Hence, further studies using different categories of age, parity of the Boran breed, and comparative study with other breeds are suggested to confirm the results in this study.

\section{Conflict of interest}

The authors declared no potential conflicts of interest relative to the research, authorship, and/or publication of this article.

\section{References}

Ali, R., Reza, M.A., Jabbar, A. and Rasool, M. H., 2006. Pathological studies on reproductive organs of zebu cow.J. Agric. Soc. Sci., 2(2), 91-95.

Arthur, G.H., Noakes, D.E. and Pearson, H., 1989. Veterinary Reproduction and Obstetrics. Bailliere Tindal. 6thEdition. Pp 19-21.

Bhajoni, M., Bhuyan, D., Biswas, R.K., and Dutta, D.J., 2018. Morphometric study of ovary and rate of recovery of the oocyte from medium size follicle by aspiration technique in cattle. Int. J. Chem. Stud., 6(2), 499-503.

Carvalho, N. A. T., Gimens, L.U., Reis, E. L. and Cavalcante, A. K. S., 2005. Biometry of the genital system from buffalo (Murrah) and bovine (Nelore) females. Guanabara Kooogan 3, 879-895.

Ethiop. Vet. J., 2021, 25 (2), 1-13 
Ali et al.,

Coppock, D.L., 1994. The Borana Plateau of Southern Ethiopia: Synthesis of pastoral research, development, and change, 1980-91. Systems Study No. 5. ILCA (International Livestock Centre for Africa), Addis Ababa, Ethiopia.

Hafeez, B. and Hafeez. E.S.E., 2000. Fertilization and cleavage in reproduction in farm animals. Hafez, B. and Hafez, E.S.E. (Eds.). Lippincott Williams and Wilkins, Philadelphia, USA. Pp: 110-125

Haile-Mariam, M.. Malmfors, B. and Philipsson, J., 1998. Boran - indigenous African cattle with potential. Currents (Sweden). no. 17/18. pp. 38-43.

Khaton, R., Sarder, M. J. U. and Gofur, M. R., 2015a. Influences of age and body weight on biometry of reproductive organs of dairy cows in Bangladesh. Int. J.Livest. Res., $5(7), 72-83$.

Khaton, R., Sarder, M. J. U. and Gofur, M. R., 2015b. Biometrical studies of reproductive organs of dairy cows of different genotypes in Bangladesh. Asian J. Anim. Sci., 9, 388-395.

Kouamo, J., Meyoufey, B., and Zoli, A. P., 2017. Biometrical study of the female reproductive tract (Bos indicus) in Cameron. Bull. Anim. Health Prod. Afr., 65, 311-320.

Kunbhar. H. K, Samo. M. U., Memon, A., and Solangi, A.A., 2003. Biometrical studies of reproductive organs of Thari cow. Pak. J. Biol. Sci.,6(4), 322-324.

Lawrence, T. E., Whatley, J. D., Montgomery, T. H. and Perino, L. J., 2001. A comparison of the USDA ossification-based maturity system to a system based on dentition. J. Anim. Sci., 79, 1683-1690.

Memon, M.A., 1996. Diagnosis of pregnancy and infertility by rectal palpation: Bovine Obstetrics. DVCS Washington State University, Pullman. Pp: 65-68. First edited by John Wiley \& Sons, 2015, Ames, Iowa 50014-8300, USA.

Moussa Garba, M., Marichatou, H., Issa, M., Abdoul Aziz, M. L., and Hanzen, C., 2013. Tractus génital des vaches zébus (Bos indicus) au Niger. Rev. Elev. Med. Vet. Pays. Trop., 66 (4), 137-142. M.

Natumanya. R., Owiny. D. and Kugonza. R., 2008. The potential of Ankole cattle abattoir ovaries for in vitro embryo production. Afr. J. Anim. Biomed. Sci., 3(1), 18194214.

Raheem, K.A., Ekechukwu, E.O., Nneka, N.V.S. and Ibiam, A., 2016. Comparative biometric study of the internal reproductive structure of White Fulani and Red Bororo cow. Appl. Trop. Agricu., 21 (1), 54-59.

Riasat, A., Muhammad, A., Abdul, J., Muhammad, H., 2006. Pathological studies on reproductive organs of zebu cow. J. Agric. Soc. Sci., 2, 91-95. 
Siddiqui, H. U. R, Ahmad, A. and Khan, M.Z., 2005. Biometrical studies of testes of ram. J. Agric. Soc. Sci., 1, 78-79.

Solomon, D., 2001. Cattle Population Dynamics in the Southern Ethiopian Rangelands. Research Global livestock collaborative research support program, (Global Livestock CRS), University of California - Davis. A Report, Research Brief 01-02-PARIMA, December 2001.

Sprinkle, J.E., Ferrell, C.L., Holloway, J.W., Warrington, B.G., Green, L.W., Wu, G. et al., 1998. Adipose tissue partitioning of limit-fed beef cattle and beef with ad libitum access to feed differing in adaptation to heat. J. Anim. Sci., 76, 665-673. 